\title{
Investigations for In-house prepared Biocompatible Feed Stock Filament of Fused Deposition Modelling: A Process Capability study
}

\author{
Nishant Ranjan ${ }^{1,2}$, Rupinder Singh ${ }^{1 *}$ and IPS Ahuja ${ }^{2}$ \\ ${ }^{1}$ Departmentof Production Engineering, Guru Nanak Dev Engineering College, Ludhiana, India \\ ${ }^{2}$ Dept. of Mechanical Engineering, Punjabi University, Patiala \\ *Corresponding e-mail: rupindersingh78@yahoo.com
}

\begin{abstract}
Fused deposition modelling (FDM) is one of the low cost additive manufacturing (AM) process. The feed stock filament of FDM is the only consumable in the process and by preparing (in-house) bio compatible feed stock filament the application domain can be increased. Some studies have reported the use of twin screw extrusion (TSE) process for preparation of bio compatible feed stock filament (comprising of polyvinyl chloride $(P V C)$ and polypropylene (PP) and hydroxyapatite (HAp) particles) with improved mechanical, dimensional and thermal properties, for commercial FDM setup. But hitherto very less has been reported on process capability of in-house prepared biocompatible feed stock filament. In the present work statistical analysis (for tensile strength, hardness and dimensional accuracy) has been performed for investigations of process capability. The results have been also supported by control charts ( $X$-chart and $R$-chart) based upon the best feedstock filament wire.
\end{abstract}

Keyword: Twin-screw extruder; Feedstock filament; HAp; PP; PVC; Control chart.

\section{INTRODUCTION}

Polymers are used extensively throughout the world because of their unique properties like: more strength to weight proportion; high temperature/chemical/destructive protection; nonconductivity; high clarity; reprocess-capacity and minimal effort. The mechanical processing of polymers is demanding very less amount of energy as compared to metals ${ }^{1-2}$. Biocompatibility is one of the most important characteristics of a biomedical polymer material whose surface is required to interact with a biological system. Such interactions between polymer surfaces and organisms have been the focus of many studies ${ }^{3-4}$. Polymers are very versatile materials and utilized as a part of numerous applications including pharmaceutical applications. Natural polymers, modified natural polymers, and synthetic polymers are used in the manufacturing of cosmetics and systems for conventional and modified delivery of drugs, by altering the composition and physical properties such as molecular weight, crystallinity and thermal transitions. They can be prepared to provide a wide range of degradation rates and mechanical properties ${ }^{5-6}$. Synthetic polymers present an attractive avenue for biocompatible biomaterials because of their well-studied syntheses and modifiable properties ${ }^{7-8}$. The biocompatibility of PVC is usually observed in invitro studies by measuring the mitochondrial dehydrogenase activity (MTT) test. The cell viability percentage higher than $80 \%$ signifies a good biocompatibility of PVC and did not present cytotoxic effect ${ }^{9}$. The PP is widely used in surgical treatment to substitute defective tissues ${ }^{10}$. The new-generation bio-compatible polymer shows excellent blood compatibility and biocompatibility and has been approved for medical use by the food and drug administration ${ }^{11}$.

In last two decades some studies have highlighted that the synthetic HAp particles were reinforced into a polymer matrix to produces composites for biomedical applications and corotating twin-screw extruder compounding produces an effective and homogeneous distribution of HAp particles in a polymers matrix, which is maintained after compression moulding ${ }^{12-}$ 13. The fillers (HAp) reinforced polymer biocomposites offer a robust system to engineer synthetic bone substitutes with tailored surgical, biological and mechanical functions; the basic design rationale has been to reinforce a tough, biocompatible polymer matrix with bioactive HAp filler ${ }^{14}$. HAp is used for skeletal tissue engineering because of its osteo-conductive and biocompatibility properties. HAp ceramics has no carcinogenic properties and does not cause trigger on allergic reactions ${ }^{15}$.

The literature review reveals that many researchers have performed parametric optimization of TSE process for preparation of FDM feedstock filament wire $^{16}$. But hitherto very less has been reported for preparation of in-house biocompatible feedstock filament for commercial FDM setup without any change in hardware or software of the system from process capability point of view. The present study is the extension of work reported by Ranjan and Singh $^{16}$, where best feed stock filament wire for 
development of partial/complete denture on the important parameter (Output diameter of feedstock filament, Shore D hardness and tensile strength) were selected for the statically analysis. The "QI Macros 2016"commercial software package for statistical analysis has been used in this work.

\section{EXPERIMENTATION}

In the previous reported study an effort has been made to prepare the feedstock filament of biocompatible grade of PVC and PP in the ratio of 70:30 (by weight) with reinforcement of filler $(\mathrm{HAp})^{16}$. For that study commercial make: HAAKE Mini CTW, Germany has been used for development of best feedstock filament wire. The feed stock filament were prepared as per Taguchi L18 $\left(2^{\wedge} 13^{\wedge} 4\right)$ orthogonal array (OA). Table 1 shows list of input factors and their levels (based upon pilot experimentation) for the experimental study. Based upon Table 1, Table 2 shows control $\log$ of experimentation. Further based upon Table 2, Fig. 1 shows the pictorial view of feed stock filament prepared.

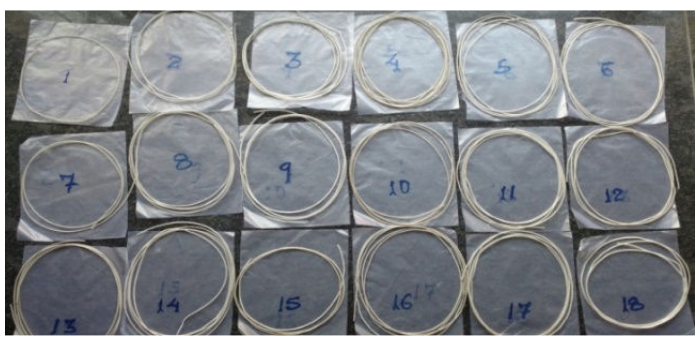

Figure 1. Prepared feedstock filament of $\mathrm{PVC}+\mathrm{PP}+\mathrm{Hap}$

Based upon Table 2, after experimental studies it was ascertained that run no. 09 (composition of materials:- $96 \mathrm{~A}+\mathrm{HAp}$ at $50 \mathrm{rpm}$ at $200^{\circ} \mathrm{C}$ temperature with $53 \mu \mathrm{mHAp}$ particles and $20 \mathrm{~kg}$ load applied) was the best feedstock filament ${ }^{16}$.

Table 1. Parameter used for experimentation

\begin{tabular}{|c|c|c|c|c|c|}
\hline$\frac{n}{0}$ & $\begin{array}{c}\text { Composition } \\
\text { of Materials } \\
\text { (\%age) }\end{array}$ & $\begin{array}{l}\text { Rotatio } \\
\text { nal } \\
\text { Speed } \\
(\mathrm{rpm})\end{array}$ & $\begin{array}{l}\text { Temp } \\
\text { eratu } \\
\text { re } \\
\left({ }^{\circ} \mathrm{C}\right)\end{array}$ & $\begin{array}{c}\text { Grain } \\
\text { size of } \\
\text { HAp } \\
(\mu \mathrm{m})\end{array}$ & $\begin{array}{l}\text { Load } \\
\text { ( Kg) }\end{array}$ \\
\hline 1 & $96 \mathrm{~A}+4$ & 30 & 180 & 53 & 10 \\
\hline 2 & $92 \mathrm{~A}+8$ & 40 & 190 & 106 & 15 \\
\hline 3 & -- & 50 & 200 & 150 & 20 \\
\hline
\end{tabular}

Note; $A-70 \%$ of $P V C \& 30 \%$ of $P P$
Table 2. Control log of experimentation

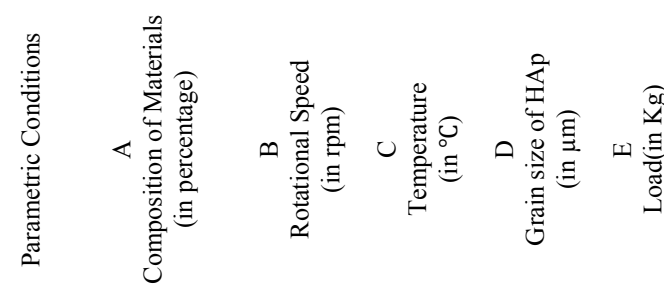

\begin{tabular}{cccccc}
\hline 1 & $96 \mathrm{~A}+4$ & 30 & 180 & 53 & 10 \\
2 & $96 \mathrm{~A}+4$ & 30 & 190 & 106 & 15 \\
3 & $96 \mathrm{~A}+4$ & 30 & 200 & 150 & 20 \\
4 & $96 \mathrm{~A}+4$ & 40 & 180 & 53 & 15 \\
5 & $96 \mathrm{~A}+4$ & 40 & 190 & 106 & 20 \\
6 & $96 \mathrm{~A}+4$ & 40 & 200 & 150 & 10 \\
7 & $96 \mathrm{~A}+4$ & 50 & 180 & 106 & 10 \\
8 & $96 \mathrm{~A}+4$ & 50 & 190 & 150 & 15 \\
9 & $96 \mathrm{~A}+4$ & 50 & 200 & 53 & 20 \\
10 & $92 \mathrm{~A}+8$ & 30 & 180 & 150 & 20 \\
11 & $92 \mathrm{~A}+8$ & 30 & 190 & 53 & 10 \\
12 & $92 \mathrm{~A}+8$ & 30 & 200 & 106 & 15 \\
13 & $92 \mathrm{~A}+8$ & 40 & 180 & 106 & 20 \\
14 & $92 \mathrm{~A}+8$ & 40 & 190 & 150 & 10 \\
15 & $92 \mathrm{~A}+8$ & 40 & 200 & 53 & 15 \\
16 & $92 \mathrm{~A}+8$ & 50 & 180 & 150 & 15 \\
17 & $92 \mathrm{~A}+8$ & 50 & 190 & 53 & 20 \\
18 & $92 \mathrm{~A}+8$ & 50 & 200 & 106 & 10 \\
\hline Note; $A-70 \%$ of $P V C \& 30 \%$ of $P P$ & &
\end{tabular}

\section{Process capability analysis}

The process capability indices (PCIs) are used in the manufacturing industry to provide numerical measures on whether a process is capable of producing items within the predetermined specification limits ${ }^{17}$. PCI is an important concept in statistical quality control and measures the ability of a process to manufacture products that meet certain specifications. It has been reported that the process capability measurements perform more accurately in evaluating the capability of a process generating a simple linear profile ${ }^{18-19}$. In this research work, "QI Macros 2016" software was used for process capability analysis by drawing various control charts.

\section{RESULT AND DISCUSSION}

Based upon observations as per Table 2, Table 3 shows the measured value of feedstock filament of three outputs (namely; diameter of feedstock filament, Shore D hardness and Peak load). The total 10 measurements were taken for drawing Xchart and mR-chart of all the three output properties. It should be noted that the diameter of feedstock filament, Shore D hardness and tensile strength (Peak load) are the most important 
parameters for development of best feedstock filament.

Table 3. Data of Peak load, Shore d hardness and diameter of wire

\begin{tabular}{cccc}
\hline \hline $\begin{array}{c}\text { Serial } \\
\text { No. }\end{array}$ & $\begin{array}{c}\text { Diameter of } \\
\text { obtained wire } \\
\text { (in mm ) }\end{array}$ & $\begin{array}{c}\text { Shore D } \\
\text { hardness } \\
\text { (in db) }\end{array}$ & $\begin{array}{c}\text { Peak Load } \\
\text { (inN) }\end{array}$ \\
\hline 1 & 1.67 & 39 & 28.38 \\
2 & 1.64 & 38 & 28.19 \\
3 & 1.68 & 38.5 & 29.26 \\
4 & 1.62 & 39 & 30.02 \\
5 & 1.63 & 39.5 & 27.69 \\
6 & 1.67 & 37 & 27.98 \\
7 & 1.66 & 37.5 & 28.55 \\
8 & 1.63 & 39 & 28.64 \\
9 & 1.65 & 39 & 29.06 \\
10 & 1.63 & 38.5 & 27.09 \\
\hline \hline
\end{tabular}

\section{Control charts}

The process capability analysis has been performed on the basis of dimensional data obtained by measuring 10 samples of feedstock filament. In order to verify that the process is statistically controlled, observed data were used to prepare $\mathrm{X}$ and $\mathrm{mR}$ charts. Fig. 2, 4 and 6 respectively shows $\mathrm{X}$ chart for diameter of feedstock filament, Shore D hardness and peak load. As observed from Fig. 2, 4 and 6 all measurement were within the upper control limit (UCL) and lower control limit (LCL). Further the range distribution was also found within the UCL and LCL (see Fig. 3, 5 and 7). Therefore it can be ascertained that the said process is under statistical control especially for batch/mass production. The mean value is 1.648 in case of diameter of feedstock filament, 38.50 in case of shore D hardness, and 28.486 in case of peak load. As observed from Fig. 2, all the 10 samples are in tolerance zone (with in UCL and LCL) and moving around its mean value 1.648 , which is acceptable for commercial FDM setup. As observed from Fig. 4 and 6 all the 10 sample with in tolerance zone and moving around its mean value. Similarly, Fig. 3,5 , and 7 shows $\mathrm{mR}$ chart of diameter, shore $\mathrm{D}$ hardness and peak load with its mean value 0.029 , 0.83 and 0.854 . So, finally it was observed that in house prepared bio compatible feed stock filament is in control limit and can be gainfully used for commercially production.

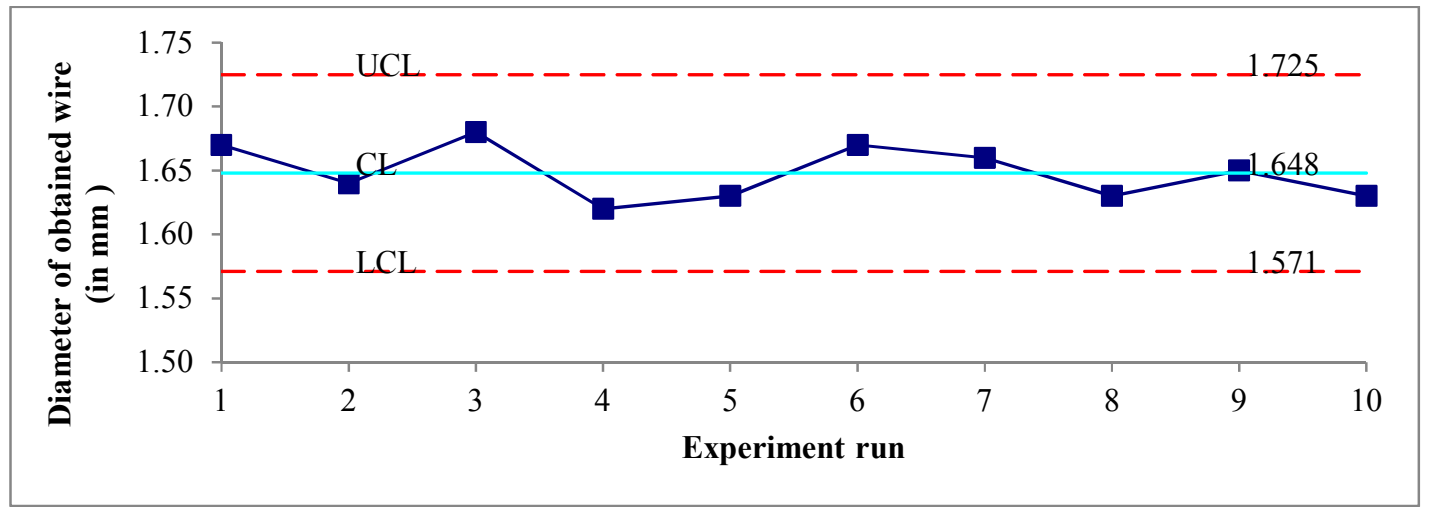

Figure 2. X chart for diameter of feedstock filament

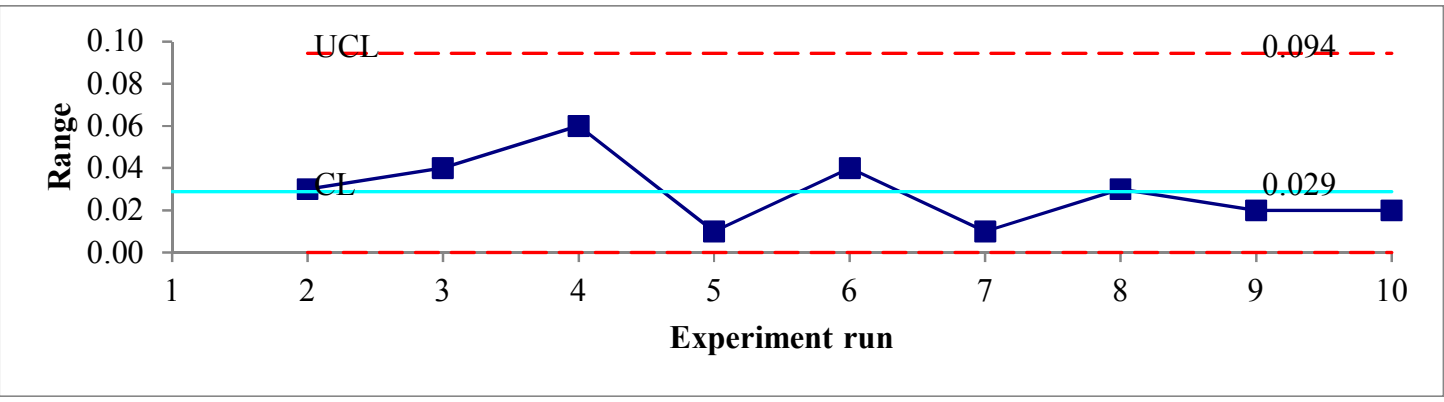

Figure 3. $\mathrm{mR}$ chart for diameter of feedstock filament 
Further based upon Table 3, Cp and Cpk values as PCI were calculated. The $\mathrm{Cp}$ and $\mathrm{Cpk}$ for feed stock filament dimensions (diameter) comes out as 1.002 . Fig. $8 \mathrm{a}$ and $8 \mathrm{~b}$ respectively shows process capability histogram and normal probability plot for feed stock filament dimensions (diameter). Similarly $\mathrm{Cp}$ and Cpk values for hardness and peak load were calculated and it has been observed that these are more than ' 1 ', which ensures that the process is statistically controlled for batch/mass production.

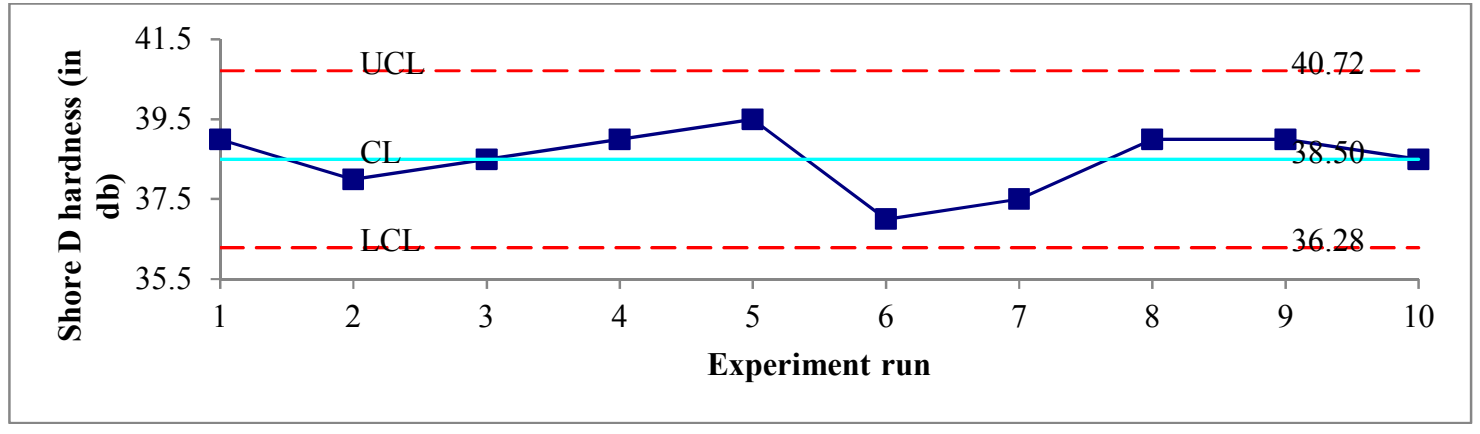

Figure 4. X chart for Shore D hardness of feedstock filament

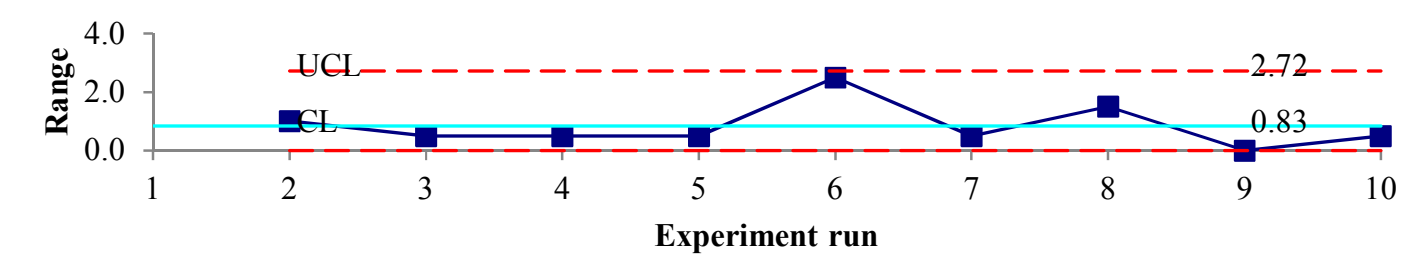

Figure 5. mR chart for Shore D hardness of feedstock filament

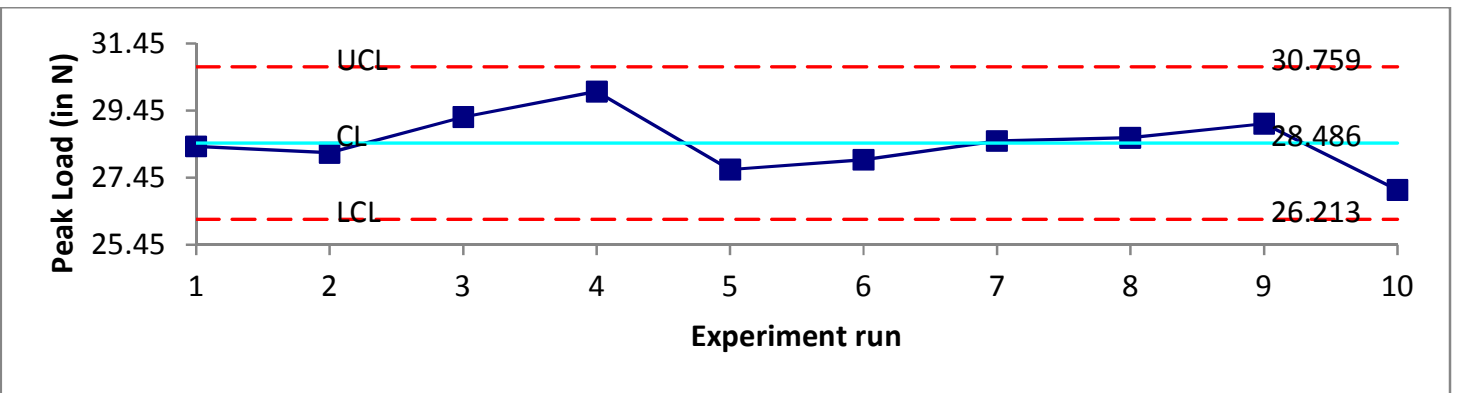

Figure 6. X-chart for Peak load of feedstock filament.

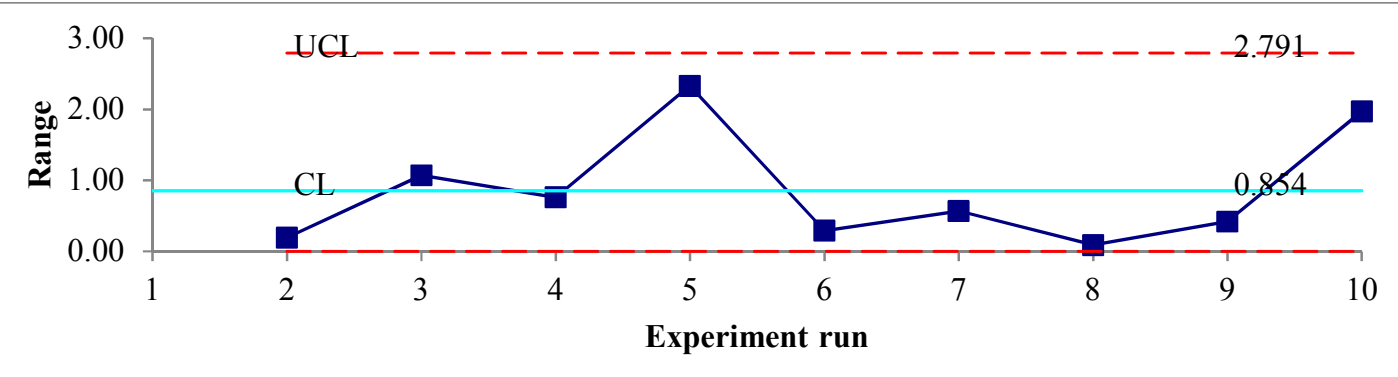

Figure 7. $\mathrm{mR}$ chart for Peak load of feedstock filament. 


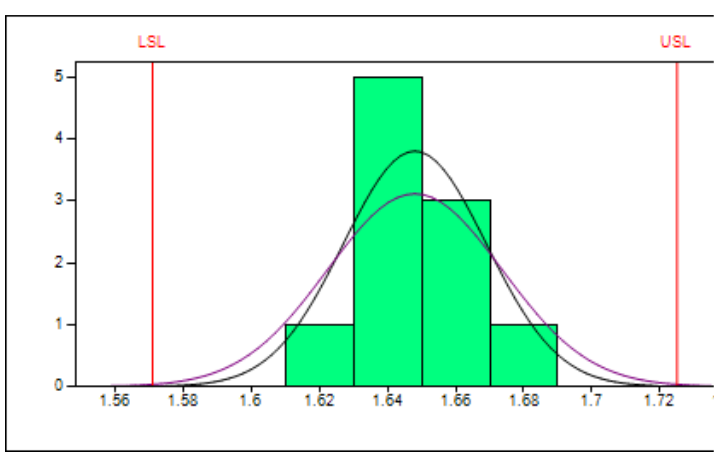

Figure 8a. Process capability histogram for dimensional measurement

\section{CONCLUSIONS}

This study highlights the statistical analysis (for tensile strength, hardness and dimensional accuracy) from process capability point of view. The study outlines the control chart (X-chart and R-chart) based upon the best feedstock filament wire. The adopted process ensures production of biocompatible functional prototypes and proof of concept at less production cost and time. Further it can be ascertained that the proposed route of preparing biocompatible feed stock filament is highly capable and expected value of PCI is grater than 1 . The results are in line with the observations made by other investigators ${ }^{16,20}$.

\section{ACKNOWLEDGMENT}

The authors are highly thankful to DST (SERB, Science and Engineering Research Board), Government of India, File. No. SERB/F/3572/2015-2016 and Institution of Engineers (India), File No. R.6/2/DR/201718/RDDR2017010 for financial support.

\section{REFERENCES}

1. Rosato, D.V., Schott, N.R. and Rosato, M.G. eds., 2001. Plastics Institute of America Plastics Engineering, Manufacturing \& Data Handbook. Springer Science \& Business Media.

2. Abeykoon, C., Kelly, A.L., Vera-Sorroche, J., Brown, E.C., Coates, P.D., Deng, J., Li, K., HarkinJones, E. and Price, M., 2014. Process efficiency in polymer extrusion: Correlation between the energy demand and melt thermal stability. Applied Energy, 135, pp.560-571.

3. Christie, R.J., 2008. Biocompatible Polymers: Design function and uses.Utsunomiyaconference,pp. 4-18, 2008.

4. Chen, H., Yuan, L., Song, W., Wu, Z. and Li, D., 2008. Biocompatible polymer materials: role of

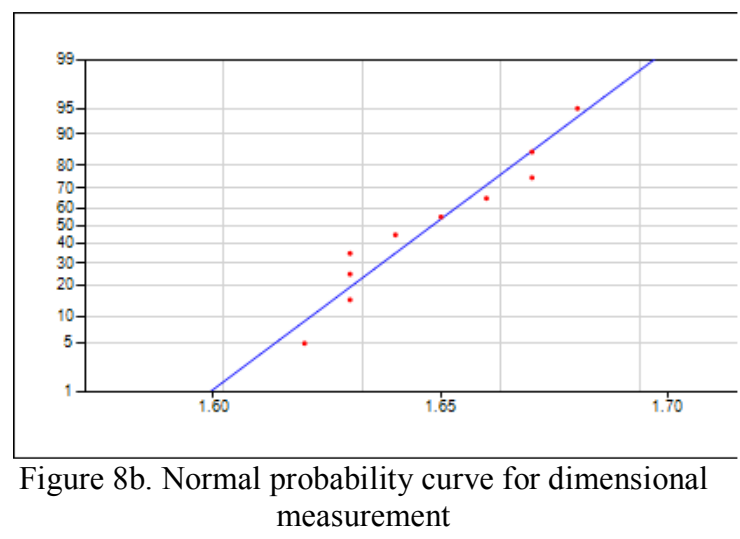

protein-surface interactions. Progress in Polymer Science, 33(11), pp.1059-1087.

5. deFreitas, I.M.S.R., 2005. Chitosan matrices for cell-based bone regenerative the rapies. $\mathrm{PhD}$ thesis. Faculdade de Egenharia, Universidade do Porto, Portugal.

6. Villanova, J.C.O. andR.L.Orefice., 2010. Application of polymers,"CienciaeTechnoligia,Vol. 20, pp. 151-64.

7. Ouchi, T. and Ohya, Y., 2004. Design of lactide copolymers as biomaterials. Journal of Polymer Science Part A: Polymer Chemistry, 42(3), pp.453462.

8. Puskas, J.E. and Chen, Y., 2004. Biomedical application of commercial polymers and novel polyisobutylene-based thermoplastic elastomers for soft tissue replacement. Biomacromolecules, 5(4), pp.1141-1154.

9. Puskas, J.E. and Chen, Y., 2004. Biomedical application of commercial polymers and novel polyisobutylene-based thermoplastic elastomers for soft tissue replacement. Biomacromolecules, 5(4), pp.1141-1154.

10. Demirer, S., Kepenekci, I., Evirgen, O., Birsen, O., Tuzuner, A., Karahuseyinoglu, S., Ozban, M. and Kuterdem, E., 2006. The effect of polypropylene mesh on ilioinguinal nerve in open mesh repair of groin hernia. Journal of Surgical Research, 131(2), pp.175-181.

11. Tanaka, M., Hayashi, T. and Morita, S., 2013. The roles of water molecules at the biointerface of medical polymers. Polymer journal, 45(7), p.701.

12. Andersen, T.E., Palarasah, Y., Skjødt, M.O., Ogaki, R., Benter, M., Alei, M., Kolmos, H.J., Koch, C. and Kingshott, P., 2011. Decreased materialactivation of the complement system using low- 
energy plasma polymerized poly (vinyl pyrrolidone) coatings. Biomaterials, 32(20), pp.4481-4488.

13. Schneider, M.,Fetsch, C., Amin, I., Jordan, R. and Luxenhofer, R., 2013. "Polypeptoid brushes by surface-initiated polymerization of $\mathrm{N}$-substituted glycine N-carboxyanhydrides. Langmuir: the ACS journal of surfaces and colloids, 29(23), p. 6983.

14. Langer, R. andTirrell, D.A., 2004. "Designing materials for biology and medicine. Nature.428(6982), pp. 487-492.

15. Porter, A.E.,Botelho, C.M.and Lopes, M.A., 2004. Ultrastructural comparison of dissolution and apatite precipitation on hydroxyapatite and siliconsubstituted hydroxyapatite in vitro and in vivo, Journal of Biomed. Mater. Re., 69, pp. 670-678

16. Ranjan, N. and Singh R., 2017. Experimental investigations for development of biocompatible feedstock filament comprising of PVC, PP and HAp for FDM,M.Tech Thesis, GNDEC Ludhiana, Punjab, India.

17. Chen, K.S.,Pearn, W.L. andLin, P.C., 2003. Capability measures for processes with multiple characteristics, Quality and Reliability Engineering International. 19, pp. 101-110.

18. Gadalla, M.A. and Popielarczyk, M., 2011. International Manufacturing Science and Engineering Conference, 2, Corvallis, Oregon, USA, June 13-17, ASME.

19. Ebadi, M.and Shahriari, H., 2013. A process capability index for simple linear profile, International Journal of Advanced Manufacturing Technology,64(5-8), pp. 857-865.

20. Singh, R. and Ranjan, N., 2017. Experimental investigations for preparation of biocompatible feedstock filament of fused deposition modeling (FDM) using twin screw extrusion process, Journal of Thermoplastic Composite Materials, DOI: $10.1177 / 0892705717738297$. 